\title{
Transition Metal-Doped Lithium Titanium Oxide Nanoparticles Made Using Flame Spray Pyrolysis
}

\author{
T. Karhunen, ${ }^{1}$ A. Lähde, ${ }^{1}$ J. Leskinen, ${ }^{1}$ R. Büchel, ${ }^{2}$ O. Waser, ${ }^{2}$ U. Tapper, ${ }^{3}$ and J. Jokiniemi ${ }^{1,3}$ \\ ${ }^{1}$ Fine Particle and Aerosol Technology Laboratory, Department of Environmental Science, University of Eastern Finland, \\ 70211 Kuopio, Finland \\ ${ }^{2}$ Particle Technology Laboratory, Department of Mechanical and Process Engineering, ETH Zürich, 8092 Zürich, Switzerland \\ ${ }^{3}$ Fine Particles, VTT Technical Research Centre of Finland, 02044 VTT, Finland \\ Correspondence should be addressed to T. Karhunen, tommi.karhunen@uef.fi
}

Received 2 August 2011; Accepted 18 September 2011

Academic Editors: B.-R. Huang and L. Y. Khomenkova

Copyright ( $) 2011$ T. Karhunen et al. This is an open access article distributed under the Creative Commons Attribution License, which permits unrestricted use, distribution, and reproduction in any medium, provided the original work is properly cited.

Defect spinel phase lithium titanate $\left(\mathrm{Li}_{4} \mathrm{Ti}_{5} \mathrm{O}_{12}\right)$ has been suggested as a promising negative electrode material for next generation lithium ion batteries. However, it suffers from low electrical conductivity. To overcome this problem conduction path length can be reduced by decreasing the primary particle size. Alternatively the bulk conductivity of $\mathrm{Li}_{4} \mathrm{Ti}_{5} \mathrm{O}_{12}$ can be increased by doping it with a conductive additive. In this paper a steady, single-step gas-phase technique for lithium titanate synthesis that combines both approaches is described. The process is used to produce doped $\mathrm{Li}_{4} \mathrm{Ti}_{5} \mathrm{O}_{12}$ nanoparticles with primary particle size of only $10 \mathrm{~nm}$. The product is found to consist of single-crystalline nanoparticles with high phase and elemental purity. Two dopant materials are tested and found to behave very differently. The silver dopant forms a separate phase of nanometre-sized particles of metallic silver which agglomerate with $\mathrm{Li}_{4} \mathrm{Ti}_{5} \mathrm{O}_{12}$. The copper dopant, on the other hand, reacts with the lithium titanate to form a double spinel phase of $\mathrm{Li}_{3}\left(\mathrm{Li}_{1-2 x} \mathrm{Cu}_{3 x} \mathrm{Ti}_{5-x}\right) \mathrm{O}_{12}$.

\section{Introduction}

Concern over the worldwide carbon dioxide emissions, as well as the dwindling oil resources, has led to increasing interest in efficient energy storage solutions for both automotive and renewable energy supply applications. At the same time advances in the miniaturization and mobility of consumer electronics are placing ever increasing pressure on the capabilities of rechargeable batteries. Currently lithium ion batteries with their high energy density and number of charge cycles are, perhaps, the best available technology to meet these demands [1]. However, for the widespread utilization of Li-ion batteries in high-demand applications such as full and hybrid electric vehicles, a number of improvements are still required. These include price, safety, specific energy and power, and the cycle life [2].

Lithium titanium oxide $\left(\mathrm{Li}_{4} \mathrm{Ti}_{5} \mathrm{O}_{12}\right.$, LTO $)$ is recognised as a promising material for the negative electrode of the next generation Li-ion batteries as it is low cost and safe and has an excellent cycle life $[2,3]$. However, it also has a few drawbacks, the major one being its low electronic conductivity.

Two solutions for this problem have been proposed. First, reducing the primary particle size of the electrode materials reduces the length of the electron diffusion paths and the local current density [4]. The high-rate capabilities of electrodes made with LTO samples from different suppliers were studied by Kavan et al. [5] who determined that there is an optimum primary particle diameter of about $17 \mathrm{~nm}$. Second, improved conductivity and rate capacity have been observed for LTO doped with transition metals such as silver [6] or copper [7]. However, the standard LTO production method of solid-state chemical reactions typically produces LTO particles with a diameter on the order of $1 \mu \mathrm{m}$ and the doping often requires a separate process thus adding to the complexity, and consequently to the cost, of production.

Single-step gas phase processes are more efficient than the solid-state ones in both the energy and raw materials required which is of great importance when scaling the 
TABLE 1: Chemicals used in the precursor solutions.

\begin{tabular}{lccc}
\hline Chemical & Supplier & Purity (\%) & CAS number \\
\hline Lithium acetylacetonate & Sigma Aldrich & 97 & $18115-70-3$ \\
Titanium tetraisopropoxide & Sigma Aldrich & 99.999 & $546-68-9$ \\
Toluene & Sigma Aldrich & 99.7 & $108-88-3$ \\
2-ethyl hexanoic acid & Sigma Aldrich & 99 & $149-57-5$ \\
Silver 2-ethyl hexanoate & Strem Chemicals & 99 & $26077-31-6$ \\
Copper 2-ethyl hexanoate & Sigma Aldrich & n.a. & $149-11-1$ \\
\hline
\end{tabular}

process up to industrial scale. Gas phase synthesis also produces particles of high purity composed of nonporous primary particles with small sizes and relatively narrow size distribution [8]. This paper describes a single-stage gas phase method for the production of silver- and copper-doped LTO. The particles were synthesised using a flame spray pyrolysis (FSP) system [9] and found to be highly pure, single crystalline nanoparticles with a primary particle size of about $10 \mathrm{~nm}$ and a uniform dopant distribution.

\section{Materials and Techniques}

2.1. Synthesis. For the liquid precursor lithium acetylacetonate (Li-acac) and titanium tetraisopropoxide (TTIP) were dissolved in stoichiometric ratio (4:5) in an equal volume mixture of toluene and 2-ethyl hexanoic acid (EHN acid), resulting in a solution with a total metal concentration of $0.5 \mathrm{M}$. The silver and copper doping was realised by adding, respectively, silver 2-ethyl hexanoate (Ag-EHN) and copper 2-ethyl hexanoate $(\mathrm{Cu}-\mathrm{EHN})$ into the precursor solution. The mass fraction of dopant metal was varied from 0 to $10 \%$ of the calculated LTO mass. The chemicals were supplied by Sigma Aldrich and Strem Chemicals (see Table 1) and used as supplied.

A flame spray pyrolysis system, shown schematically in Figure 1, was used for the $\mathrm{Li}_{4} \mathrm{Ti}_{5} \mathrm{O}_{12}$ synthesis. In FSP the precursor solution is fed through a capillary in the middle of the device. The liquid feed is then atomised with high-pressure dispersion gas fed through an annular aperture around the capillary tube; the droplet size is determined by the dispersion gas flow rate [9]. A premixed methane-oxygen flamelet ignites the aerosolized precursor solution resulting in the formation of a high-temperature flame, with temperatures in excess of $2000 \mathrm{~K}$ [9], within which the organometallic precursors decompose and the organic compounds undergo complete combustion, forming carbon dioxide and water vapour.

The metallic or semimetallic components of the precursor will then nucleate and condensate to form primary particles of pure metals (e.g., silver) or oxides (e.g., $\mathrm{SiO}_{2}$ or $\left.\mathrm{Li}_{4} \mathrm{Ti}_{5} \mathrm{O}_{12}\right)$. Some aggregation will take place in the hightemperature region of the flame but rapid quenching due to efficient radiation and convection quickly stops the sintering [10]. Thus the primary particles will remain small though they do form loose agglomerates in the gas stream, due to high particle concentration, and further during powder collection.

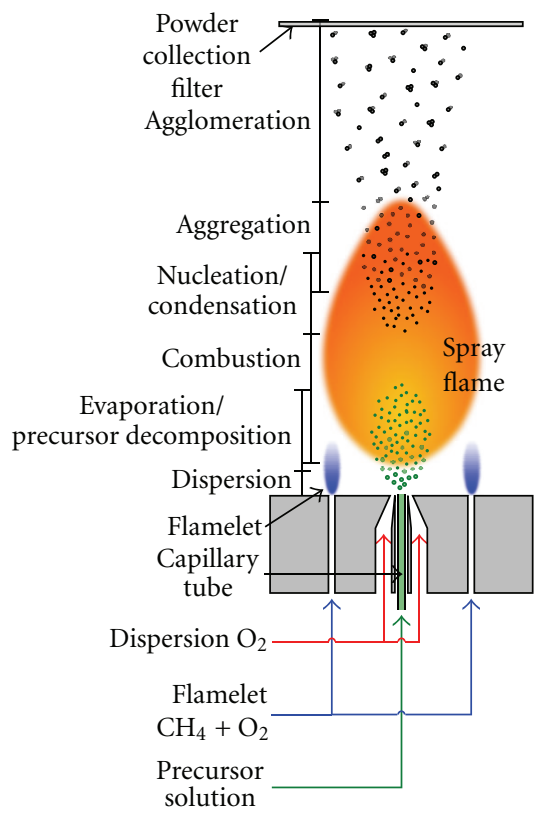

Figure 1: Schematic of the flame spray pyrolysis system and the particle formation process.

2.2. Analysis Techniques. As FSP synthesis takes place in the gas phase, aerosol instruments can be utilized to study the product particles in real time. The raw particle concentration, however, was too high for the analyser and thus a dilution system was set up. This system is illustrated in Figure 2. The sample flow with a rate of $12 \mathrm{~L} / \mathrm{min}$ is diluted with a porous tube diluter (PRD) and two ejector diluters (ED) [11] in series to achieve a total dilution ratio (DR) of about 240. Filtered and dried air regulated with mass flow controllers (MFC) was used for the dilution.

The diluted sample is analysed using a condensation particle counter (CPC, TSI CPC 3775) [12] and a fast mobility particle sizer (FMPS, TSI FMPS 3091) [13]. CPC provides high time-resolution measurement of the total particle number concentration and is thus ideal for monitoring temporal variations in the synthesis process. FMPS, on the other hand, measures the size distribution of the synthesised particles. Hence, information about the aggregates formed during the synthesis can be obtained before agglomeration in powder collection.

To determine the size of the primary particles the BET technique [14] was used. To remove any adsorbed water the 


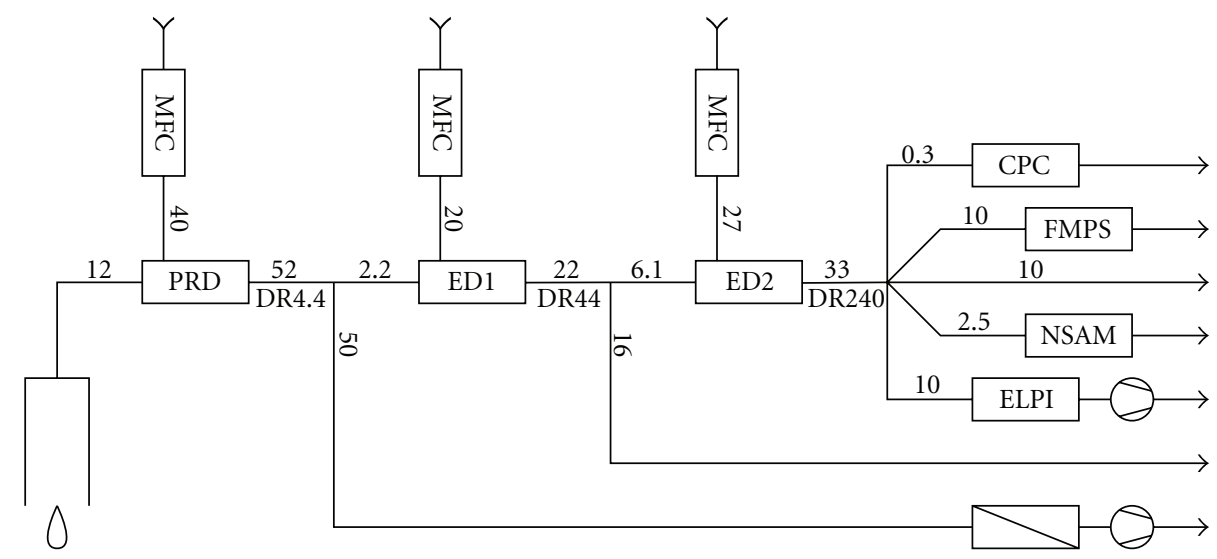

FIGURE 2: Schematic of the dilution set-up used for measuring the LTO aerosol produced by FSP. Approximate flows (in L/min) and dilution ratios are also shown.

powders were first dried at $150^{\circ} \mathrm{C}$ for at least one hour at atmospheric pressure. The specific surface area (SSA) was determined by a five-point nitrogen adsorption isotherm at $77 \mathrm{~K}$ using Tristar gas adsorption instrument (Micrometrics Instruments Corp.). The primary particle size can then be calculated from (1) (using the bulk density of LTO: $\rho=$ $\left.3.477 \mathrm{~g} / \mathrm{cm}^{3}\right)$ :

$$
d_{\mathrm{BET}}=\frac{6}{\rho \times \mathrm{SSA}} .
$$

X-ray diffraction (XRD) was performed on a Bruker AXS D8 Advance $(\mathrm{Cu} \mathrm{K} \alpha$ source, $40 \mathrm{kV}, 40 \mathrm{~mA})$ and analysed with the Topas 3 software. The diffraction was measured between $2 \theta$ angles of 10 and $80^{\circ}$ with step size of $0.06^{\circ}$. The crystal sizes, $d_{\mathrm{XRD}}$, were calculated based on the fundamental parameter approach and the Rietveld method [15].

The elemental purity was determined by X-ray fluorescence using a Philips PW2404 X-ray spectrometer. From this a semiquantitative elemental analysis was obtained using the SemiQ program.

Finally, the samples were imaged using a high-resolu-tion transmission electron microscope (Philips CM-200 FEG/ STEM, FEI company). Both light and dark field images were obtained, as well as energy dispersive spectrograms (EDS) of selected points. To prepare the samples the powders were first dispersed into ethanol without sonication. An EM grid was then dipped into the dispersion and allowed to dry in room temperature before the imaging.

\section{Results and Discussion}

3.1. Pure $\mathrm{Li}_{4} \mathrm{Ti}_{5} \mathrm{O}_{12}$. As FSP produces particles in the gasphase, the temporal variations of the process can be studied by using real-time aerosol analysers. Figure 3 shows the number concentration of FSP-produced $\mathrm{Li}_{4} \mathrm{Ti}_{5} \mathrm{O}_{12}$. It can be easily seen that the concentration ramps up quickly to few times $10^{8} \mathrm{~cm}^{-3}$ (dilution corrected) once the precursor feed is turned on. Similarly, when the feed is turned off, the concentration drops off very quickly.

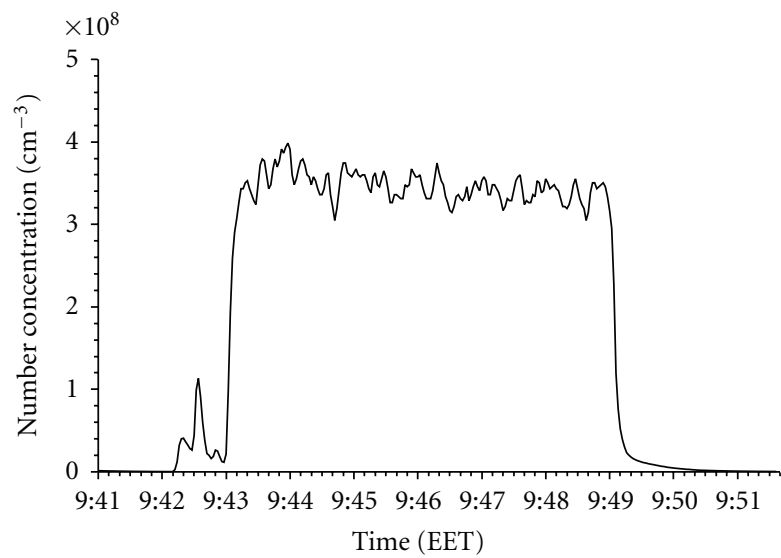

FIGURE 3: Agglomerate number concentration during LTO production measured with CPC.

The particle number size distribution from the beginning (solid, after $1 \mathrm{~min}$ ), the middle (dashed, after $3 \mathrm{~min}$ ), and the end (dotted, after $5 \mathrm{~min}$ ) of the precursor feed is shown in Figure 4. It is evident that the distribution remains nearly constant throughout the experiment with only slight decrease in the number concentration and increase in the average particle size. It can also be seen that the geometric mean particle size is about $80 \mathrm{~nm}$.

The elemental purity of the FSP-produced LTO powder was verified using semiquantitative X-ray fluorescence analysis. With this method elements heavier than fluorine, excluding noble gases, can be detected with a sensitivity limit of about $0.1 \%$. The elements exceeding this limit are listed in Table 2.

Only small amounts of impurities were found with the major ones being fluorine and silicon. The former is likely an artefact due to lighter elements as there was no fluorine present in the synthesis, while the latter is most likely contamination by the filter material used. The fraction of $\mathrm{Li}_{4} \mathrm{Ti}_{5} \mathrm{O}_{12}$ in the powder was determined to be over $99 \%$.

Also the phase purity of the powder was determined. The $\mathrm{X}$-ray diffractiogram for the pure LTO is shown at the bottom 


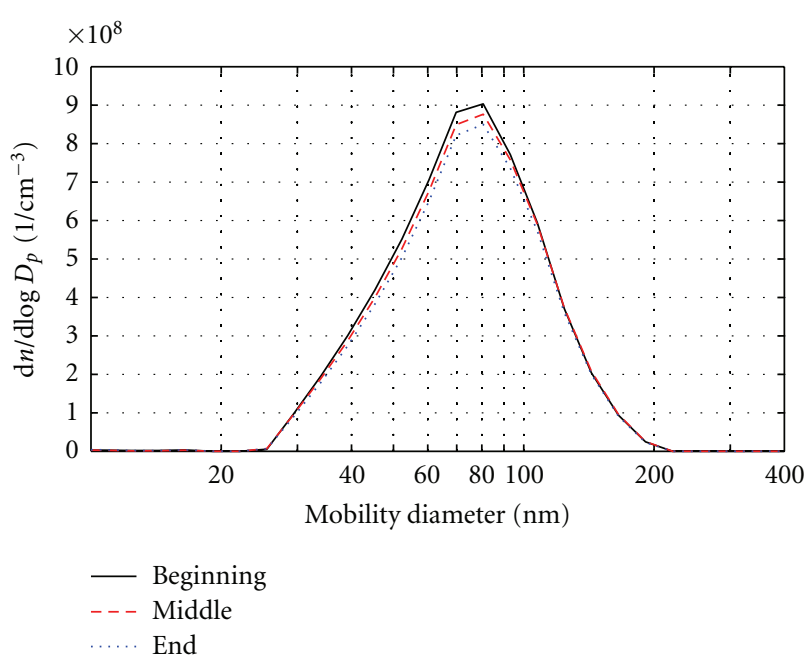

FIgURE 4: Agglomerate mobility size distribution during LTO production measured with FMPS.

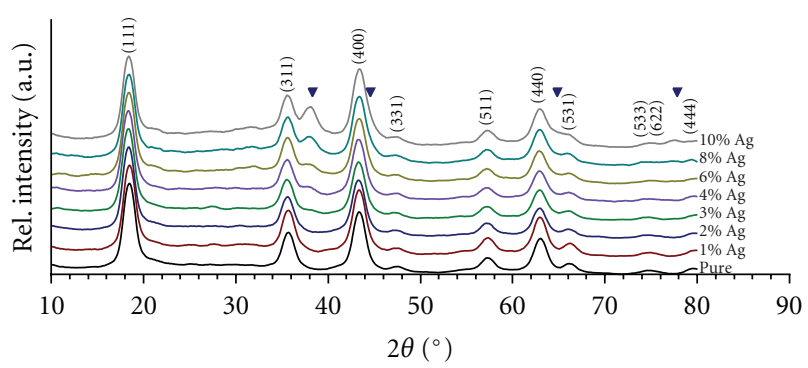

FIGURE 5: X-ray diffraction spectra for silver-doped LTO.

TABLE 2: Semiquantitative X-ray fluorescence analysis of FSP made $\mathrm{Li}_{4} \mathrm{Ti}_{5} \mathrm{O}_{12}$ powder.

\begin{tabular}{lc}
\hline Element & Fraction $(\%)$ \\
\hline Titanium & 52 \\
Fluorine & 0.3 \\
Silicon & 0.15 \\
Sodium & 0.07 \\
Chlorine & 0.04 \\
Aluminium & 0.02 \\
Calcium & 0.02 \\
$\mathrm{Zinc}{ } \mathrm{Ti}_{5} \mathrm{O}_{12}$ & 0.02 \\
\hline${ }^{*} \mathrm{Calculated} \mathrm{from} \mathrm{the} \mathrm{titanium} \mathrm{fraction.}$ & $99.1^{*}$ \\
\hline
\end{tabular}

of Figure 5 while the Miller indices for the main peaks of $\mathrm{Li}_{4} \mathrm{Ti}_{5} \mathrm{O}_{12}$ spinel phase are listed at the top of the figure [3]. It is clear that no significant phase impurities exist. Thus, in addition to high elemental purity the produced powder has high phase purity.

One of the advantages of gas-phase synthesis over solidstate or slurry processes is the small primary particle size or large specific surface area (SSA). This was measured for the LTO powder using the nitrogen adsorption technique (BET). The surface area for the pure LTO was found to be

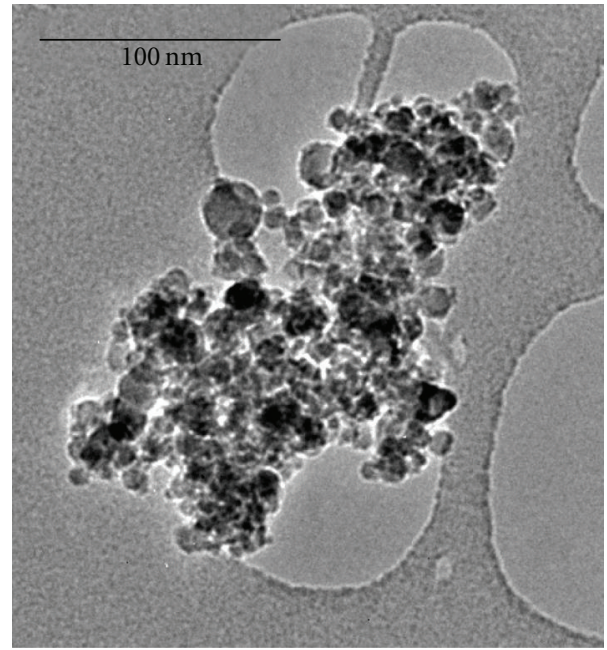

FIgURE 6: TEM image of a single aggregate of $\mathrm{Li}_{4} \mathrm{Ti}_{5} \mathrm{O}_{12}$.

about $170 \mathrm{~m}^{2} / \mathrm{g}$ which corresponds to a primary particle size of about $10 \mathrm{~nm}$. This is equal to the crystal size $(9.9 \mathrm{~nm})$ as determined by the Rietveld method from the XRD diffractiograms.

A more detailed look of the particles produced with the FSP technique was obtained using transmission electron microscopy. Figure 6 shows an image of a single aggregate particle of undoped LTO formed during the gas-phase synthesis. It is about $100 \mathrm{~nm}$ in diameter and contains a few hundred loosely packed primary particles corresponding well with the aerosol measurements. It can also be verified that the primary particles are spherical and fairly uniform in size.

Thus it can be concluded that $\mathrm{Li}_{4} \mathrm{Ti}_{5} \mathrm{O}_{12}$ single crystalline nanoparticles with high elemental and phase purity can be produced using flame spray pyrolysis. The chemical reaction taking place in the gas phase can be written as in (2) (required $\mathrm{O}_{2}$ and produced $\mathrm{CO}_{2}$ and $\mathrm{H}_{2} \mathrm{O}$ are implied):

$$
4 \mathrm{Li}\left(\mathrm{C}_{5} \mathrm{H}_{7} \mathrm{O}_{2}\right)+5 \mathrm{Ti}\left(\mathrm{C}_{3} \mathrm{H}_{7} \mathrm{O}\right)_{4} \rightarrow \mathrm{Li}_{4} \mathrm{Ti}_{5} \mathrm{O}_{12} .
$$

This reaction is, however, sensitive to the molar ratio of lithium and titanium in the precursor. Excess lithium or titanium will result in the appearance of a second phase of rutile $\left(\mathrm{TiO}_{2}\right)$ or ordered $\mathrm{Li}_{2} \mathrm{TiO}_{3}$, respectively [16].

3.2. Doped $\mathrm{Li}_{4} \mathrm{Ti}_{5} \mathrm{O}_{12}$. The effect of the doping on the FSP produced LTO was studied by comparing the X-ray diffractiograms for samples with increasing dopant content. These are shown in Figures 5 and 7 for the silver- and copperdoped powders, respectively. The diffractiograms correspond very well to those presented in literature $[6,7]$ except that the diffraction peaks are much wider due to smaller crystal size.

The locations of the diffraction peaks of crystalline silver are indicated by the triangles in Figure 5. These peaks appear and increase as the silver content on the powder increases. Thus it can be deduced that the silver forms a crystalline phase separated from the LTO. Hence a nanoparticulate $\mathrm{LTO} / \mathrm{Ag}$ composite is obtained. 


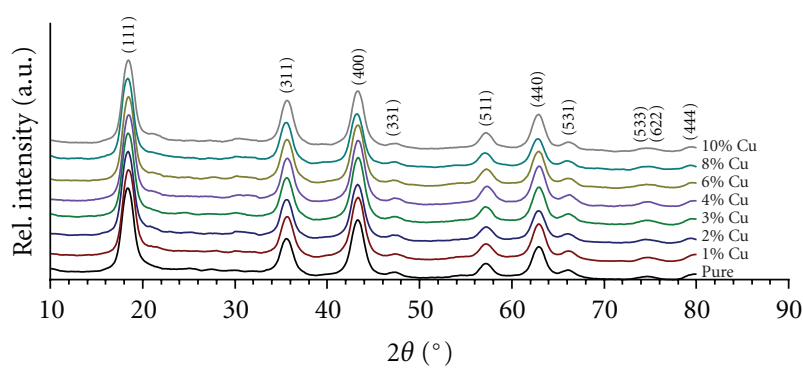

Figure 7: X-ray diffraction spectra for copper-doped LTO.

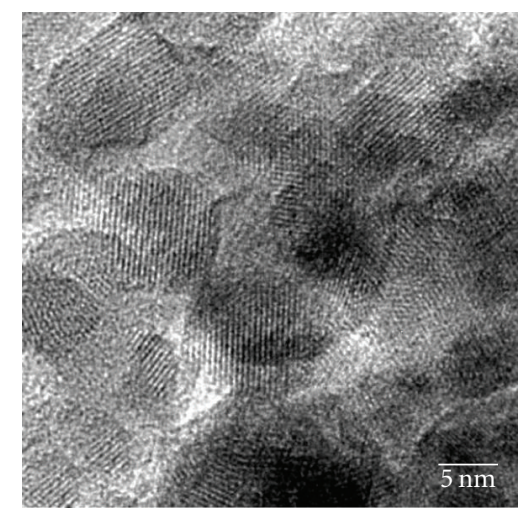

(a)

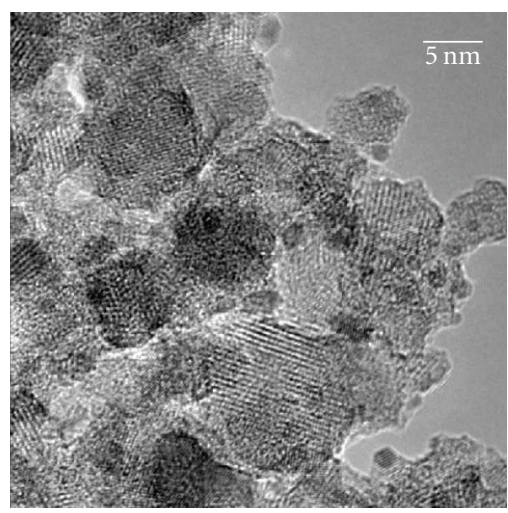

(b)

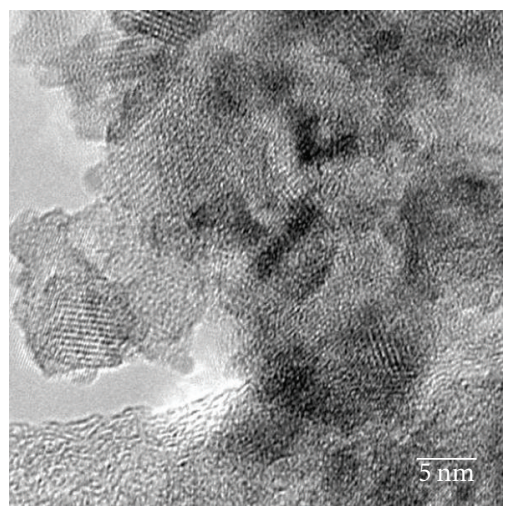

(c)

Figure 8: High-resolution TEM images of (a) undoped, (b) silverdoped, and (c) copper-doped LTO.
On the other hand, no additional phases appear for the copper-doped samples. Instead the intensity of the (311) peak relative to the (400) peak increases with increasing copper content. This was explained by Wang et al. [7] as a result of the formation of a $\mathrm{Li}_{4} \mathrm{Ti}_{5} \mathrm{O}_{12}-\mathrm{Li}_{2} \mathrm{CuTi}_{3} \mathrm{O}_{8}$ double spinel structure. Thus, unlike the silver, the copper doping enters the crystal structure of $\mathrm{Li}_{4} \mathrm{Ti}_{5} \mathrm{O}_{12}$; two lithium and one titanium atoms at the $16 \mathrm{~d}$-sites of the spinel are replaced by copper atoms.

Also the specific surface area was measured for the samples of differing dopant content. It was found that the SSA decreases as expected due to the additional mass. When the added mass is taken into consideration, the specific area is roughly constant. Thus it appears that doping does not have a significant effect on the primary particle size.

Finally, the details of the effects of the doping on the synthesised particles were studied with high-resolution TEM imaging. These are shown in Figure 8 for the undoped (Figure 8(a)), and silver- (Figure 8(b)) and copper(Figure 8(c)) doped $\mathrm{Li}_{4} \mathrm{Ti}_{5} \mathrm{O}_{12}$. In all three cases crystalline regions of LTO around $10 \mathrm{~nm}$ in size can be seen. These match the crystalline size determined by the XRD analyses as well as the primary particle size.

For the silver-doped LTO a separate phase of nanoparticles with diameter of only about $1 \mathrm{~nm}$ can be clearly seen (Figure 8(b)). These were identified as metallic silver using energy dispersive spectroscopy. Thus it seems evident that the silver forms a separate phase of nanoparticles which then deposit on and between the LTO particles. No such phase separation is evident for the copper-doped powder.

In light of the above results it seems evident that the silver doping and copper doping behave very differently during the FSP synthesis of $\mathrm{Li}_{4} \mathrm{Ti}_{5} \mathrm{O}_{12}$. The silver seems to form metallic silver particles according to (3) leading to LTO/Agcomposite:

$$
\begin{gathered}
4 \mathrm{Li}\left(\mathrm{C}_{5} \mathrm{H}_{7} \mathrm{O}_{2}\right)+5 \mathrm{Ti}\left(\mathrm{C}_{3} \mathrm{H}_{7} \mathrm{O}\right)_{4}+x \mathrm{Ag}\left(\mathrm{C}_{8} \mathrm{H}_{15} \mathrm{O}_{2}\right) \\
\longrightarrow \mathrm{Li}_{4} \mathrm{Ti}_{5} \mathrm{O}_{12}+x \mathrm{Ag}
\end{gathered}
$$

On the other hand, the copper appears to react with the other precursors to form an altered spinel phase of $\mathrm{Li}_{2} \mathrm{CuTi}_{3} \mathrm{O}_{8}$ in solid solution with $\mathrm{Li}_{4} \mathrm{Ti}_{5} \mathrm{O}_{12}$. The chemical reaction in this case is given by (4):

$$
\begin{aligned}
& 4 \mathrm{Li}\left(\mathrm{C}_{5} \mathrm{H}_{7} \mathrm{O}_{2}\right)+5 \mathrm{Ti}\left(\mathrm{C}_{3} \mathrm{H}_{7} \mathrm{O}\right)_{4}+x \mathrm{Cu}\left(\mathrm{C}_{8} \mathrm{H}_{15} \mathrm{O}_{2}\right)_{2} \\
& \quad \longrightarrow\left(1-\frac{2}{3} x\right) \mathrm{Li}_{4} \mathrm{Ti}_{5} \mathrm{O}_{12}+x \mathrm{Li}_{2} \mathrm{CuTi}_{3} \mathrm{O}_{8}+\frac{1}{3} x \mathrm{Li}_{2} \mathrm{TiO}_{3}
\end{aligned}
$$

As can be seen the reaction would require also the formation of $\mathrm{Li}_{2} \mathrm{TiO}_{3}$. However, the main X-ray diffraction peaks of this phase coincide with peaks of $\mathrm{Li}_{4} \mathrm{Ti}_{5} \mathrm{O}_{12}$ which makes the two difficult to tell apart.

Although the two dopants behave differently during the synthesis, both the LTO/Ag composite and the LTO/Cu double spinel have been shown in the literature to have improved conductivity compared to the undoped $\mathrm{Li}_{4} \mathrm{Ti}_{5} \mathrm{O}_{12}$ $[6,7]$. 


\section{Conclusions}

This paper describes a gas-phase technique for simultaneous synthesis and doping of $\mathrm{Li}_{4} \mathrm{Ti}_{5} \mathrm{O}_{12}$ nanoparticles. The synthesis process was found to be fast and steady. The resulting single crystalline particles had a diameter of about $10 \mathrm{~nm}$ and a high elemental and phase purity. Formation of aggregates with hundreds of these primary particles was observed in the gas phase with further agglomeration during the powder collection.

Both silver and copper doping of the LTO particles was studied. The two dopants were found to behave very differently. The silver formed a separate phase of metallic silver that deposited on and between the LTO particles, leading to an LTO/Ag composite material. The copper, on the other hand, reacted with the LTO to form a double spinel structure.

For both cases similar results have been reported in the literature for LTO produced with solid-state techniques and found to lead to increased conductivity of the material. This is also evident from preliminary results of electrochemical tests conducted with FSP made LTO. Thus it is evident that flame spray pyrolysis is a powerful technique for the synthesis of doped $\mathrm{Li}_{4} \mathrm{Ti}_{5} \mathrm{O}_{12}$ nanoparticles with high purity and small primary particle size.

\section{Acknowledgments}

This work was supported in part by the Finnish Funding Agency for Technology and Innovation and by the Fortum Foundation. T. Karhunen, A. Lähde, J. Leskinen, and J. Jokiniemi acknowledge the support by the strategic funding of the University of Eastern Finland under the project Novel nanostructured materials for pharmaceutical, biomedical and environmental applications (Namber). R. Büchel and O. Waser thank for the support of European Research Council/European Community (under FP7).

\section{References}

[1] P. J. Hall and E. J. Bain, "Energy-storage technologies and electricity generation," Energy Policy, vol. 36, no. 12, pp. 43524355, 2008.

[2] A. du Pasquier, I. Plitz, S. Menocal, and G. Amatucci, "A comparative study of Li-ion battery, supercapacitor and nonaqueous asymmetric hybrid devices for automotive applications," Journal of Power Sources, vol. 115, no. 1, pp. 171-178, 2003.

[3] T. Ohzuku, A. Ueda, and N. Yamamoto, "Zero-strain insertion material of $\mathrm{Li}\left[\mathrm{Li}_{1 / 3} \mathrm{Ti}_{5 / 3}\right] \mathrm{O}_{4}$ for rechargeable lithium cells," Journal of the Electrochemical Society, vol. 142, no. 5, pp. 14311435, 1995.

[4] A. S. Aricò, P. Bruce, B. Scrosati, J. M. Tarascon, and W. van Schalkwijk, "Nanostructured materials for advanced energy conversion and storage devices," Nature Materials, vol. 4, no. 5, pp. 366-377, 2005.

[5] L. Kavan, J. Procházka, T. M. Spitler et al., "Li insertion into $\mathrm{Li}_{4} \mathrm{Ti}_{5} \mathrm{O}_{12}$ (spinel). Charge capability vs. particle size in thinfilm electrodes," Journal of the Electrochemical Society, vol. 150, no. 7, pp. A1000-A1007, 2003.
[6] S. Huang, Z. Wen, J. Zhang, and X. Yang, "Improving the electrochemical performance of $\mathrm{Li}_{4} \mathrm{Ti}_{5} \mathrm{O}_{12} / \mathrm{Ag}$ composite by an electroless deposition method," Electrochimica Acta, vol. 52, no. 11, pp. 3704-3708, 2007.

[7] D. Wang, H. Y. Xu, M. Gu, and C. H. Chen, " $\mathrm{Li}_{2} \mathrm{CuTi}_{3} \mathrm{O}_{8}$ $\mathrm{Li}_{4} \mathrm{Ti}_{5} \mathrm{O}_{12}$ double spinel anode material with improved rate performance for Li-ion batteries," Electrochemistry Communications, vol. 11, no. 1, pp. 50-53, 2009.

[8] H. K. Kammler, L. Mädler, and S. E. Pratsinis, "Flame synthesis of nanoparticles," Chemical Engineering and Technology, vol. 24, no. 6, pp. 583-596, 2001.

[9] L. Mädler, H. K. Kammler, R. Mueller, and S. E. Pratsinis, "Controlled synthesis of nanostructured particles by flame spray pyrolysis," Journal of Aerosol Science, vol. 33, no. 2, pp. 369-389, 2002.

[10] R. Strobel and S. E. Pratsinis, "Flame aerosol synthesis of smart nanostructured materials," Journal of Materials Chemistry, vol. 17, no. 45, pp. 4743-4756, 2007.

[11] J. Tissari, O. Sippula, J. Kouki, K. Vuorio, and J. Jokiniemi, "Fine particle and gas emissions from the combustion of agricultural fuels fired in a $20 \mathrm{~kW}$ burner," Energy and Fuels, vol. 22, no. 3, pp. 2033-2042, 2008.

[12] G. J. Sem, "Design and performance characteristics of three continuous-flow condensation particle counters: a summary," Atmospheric Research, vol. 62, no. 3-4, pp. 267-294, 2002.

[13] G. Biskos, K. Reavell, and N. Collings, "Description and theoretical analysis of a differential mobility spectrometer," Aerosol Science and Technology, vol. 39, no. 6, pp. 527-541, 2005.

[14] S. Brunauer, P. H. Emmett, and E. Teller, "Adsorption of gases in multimolecular layers," Journal of the American Chemical Society, vol. 60, no. 2, pp. 309-319, 1938.

[15] R. W. Cheary and A. Coelho, "Fundamental parameters approach to X-ray line-profile fitting," Journal of Applied Crystallography, vol. 25, no. 2, pp. 109-121, 1992.

[16] D. C. Johnston, "Superconducting and normal state properties of $\mathrm{Li}_{1+x} \mathrm{Ti}_{2-x} \mathrm{O}_{4}$ spinel compounds. I. Preparation, crystallography, superconducting properties, electrical resistivity, dielectric behavior, and magnetic susceptibility," Journal of Low Temperature Physics, vol. 25, no. 1-2, pp. 145-175, 1976. 

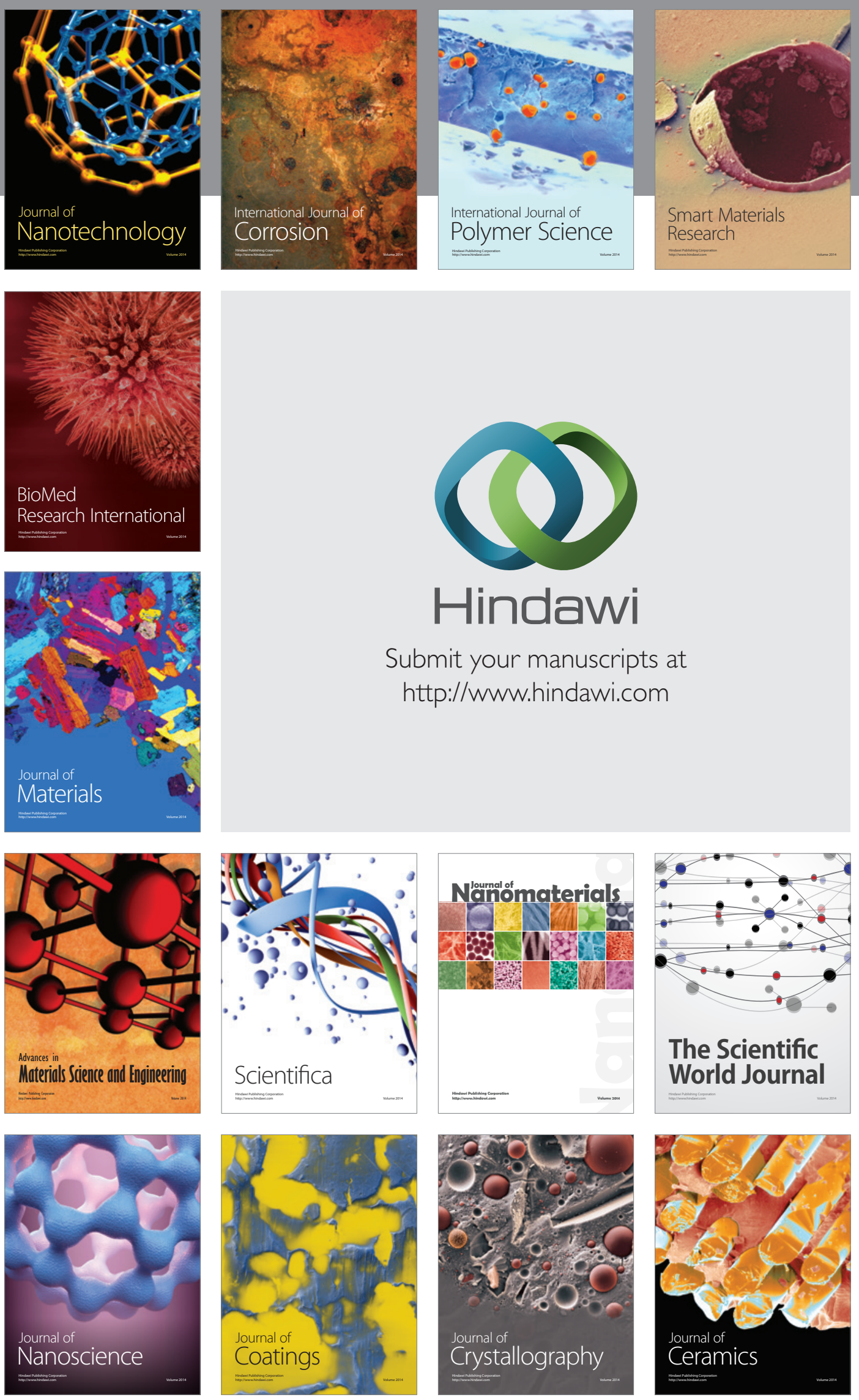

The Scientific World Journal

Submit your manuscripts at

http://www.hindawi.com

\section{World Journal}

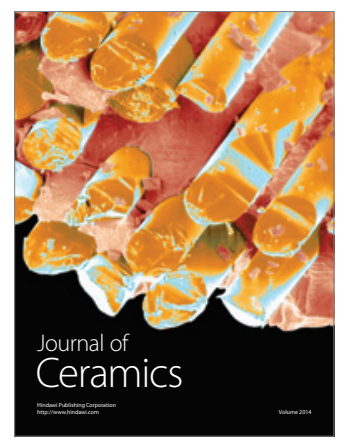

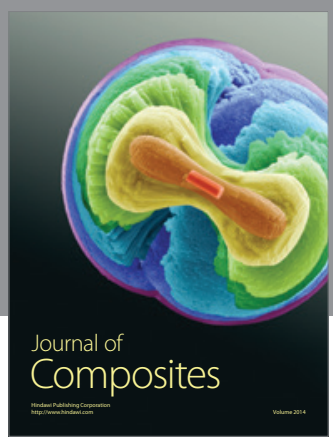
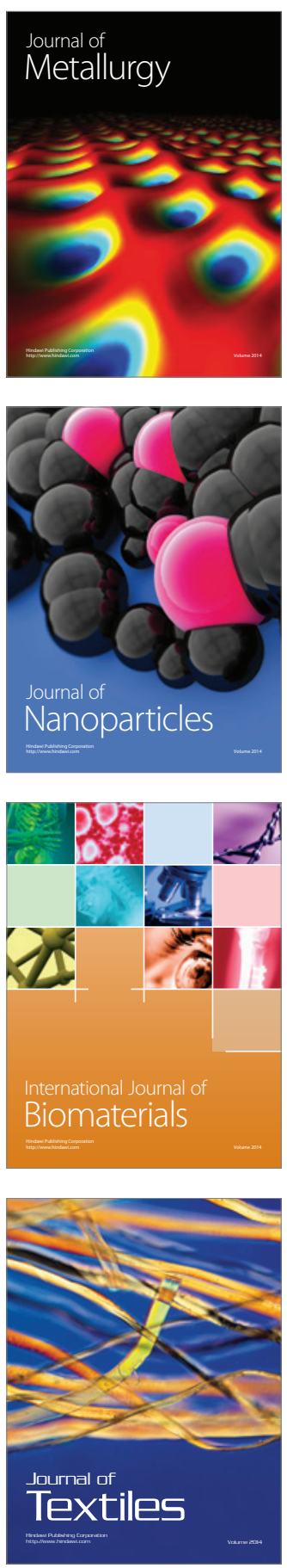